\title{
Polyp detection rates as quality indicator in clinical versus screening colonoscopy
}

\section{다 (i)}

\author{
Authors

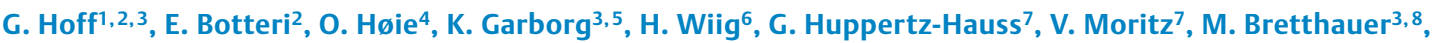 \\ Ø. Holme $2,3,6$
}

Institutions

1 Department of Research, Telemark Hospital, Skien, Norway

2 Cancer Registry of Norway, Oslo, Norway

3 Clinical Effectiveness Research group, Institute of Health and Society, University of Oslo, Oslo, Norway

4 Department of Medicine, Sørlandet Hospital, Arendal, Norway

5 Department of Transplantation Medicine, Oslo University Hospital, Oslo, Norway

6 Department of Medicine, Sørlandet Hospital, Kristiansand, Norway

7 Department of Medicine, Telemark Hospital, Skien, Norway

8 Frontier Science Foundation, Boston, MA, USA

submitted 27.7.2018

accepted after revision 24.9.2018

Bibliography

DOI https://doi.org/10.1055/a-0796-6477 |

Endoscopy International Open 2019; 07: E195-E202

(c) Georg Thieme Verlag KG Stuttgart · New York

ISSN 2364-3722

Corresponding author

Geir Hoff, Dept. of Research, Telemark Hospital, Skien, Norway

Fax: +47-35-004132

hofg@online.no

\section{ABSTRACT}

Background Adenoma and Polyp Detection Rates (ADR and PDR) are advocated as general performance measures for screening and clinical colonoscopy, but their evidence is largely derived from screening data. This study compares PDRs in colonoscopy for screening versus clinical indications.

Methods Consecutive patients at two Norwegian centers were examined by eight endoscopists either for colonoscopy screening in a randomized colonoscopy screening trial (Nordic-European Initiative on Colorectal Cancer, NordICC) or for clinical indications during the same time period (January 2013 to December 2014). PDR-5 mm, defined as the proportion of colonoscopies with detection of at least one polyp with diameter $\geq 5 \mathrm{~mm}$, was measured prospectively. We fitted multivariable logistic regression models and calculated the adjusted odds ratios (OR) to evaluate factors for differences in PDR- $5 \mathrm{~mm}$ between screening and clinical colonoscopies.

Results The study included 2939 clinical and 771 screening colonoscopies. The PDR-5mm was $26 \%$ and $31 \%$, respectively $(P=0.005)$. Among sex, age, cecum intubation, bowel cleansing, and endoscopist, only the latter explained the higher PDR-5 mm in screening compared to routine colonoscopy. In the fully adjusted logistic regression model, the detection of polyps $\geq 5 \mathrm{~mm}$ was not associated with indication for colonoscopy. The OR for polyp detection in screening vs. routine colonoscopy was 1.04; $95 \%$ confidence interval $0.85-1.27$.

Conclusion In this study, the differences in PDR- $5 \mathrm{~mm}$ between clinical and screening colonoscopies could be explained by the endoscopist. Accordingly, PDR- $5 \mathrm{~mm}$ benchmarks may be similar for clinical and screening colonoscopy.

\section{Background}

The importance of adenoma detection and polypectomy for colorectal cancer (CRC) prevention has been well documented $[1,2]$. Benchmarking adenoma detection rates (ADR), however, has been largely based on data from colonoscopy screening performed on average risk individuals older than 50 years of age. For primary screening colonoscopy in the USA, current ADR targets are $>30 \%$ for men and $>20 \%$ for women [3]. For colonoscopy performed for clinical indications, other ADR targets may be more appropriate, depending on patient mix and local surveillance policies. 
ADR is a cumbersome quality indicator since it requires pathologic evaluation of all polyps. Polyp detection rate (PDR) is a more convenient measure as it is readily available from endoscopy reports, but may be more prone to gaming than ADR, as histology confirmation is missing. Polypectomy rates of $40 \%$ and $30 \%$ have been found to correlate with ADRs of $25 \%$ and $15 \%$ for men and women, respectively $[4,5]$ and PDR is a strong proxy candidate for ADR. These were the recommended ADRs for men and women in the USA until 2015 [2,3]. European guidelines for colonoscopy in general (not only screening) have defined an overall aim of $40 \%$ PDR and $25 \%$ ADR [6]. These quality measures may vary between not only colonoscopists, but they may also depend on background population, age, clinical setting, patient mix, and bowel cleansing.

In the present study, we have compared PDR in screening colonoscopy and colonoscopy performed for clinical indication. The procedures were performed at two hospitals serving the same background population and with the same colonoscopists providing both routine and screening colonoscopy services.

\section{Methods}

The study was carried out at Kristiansand and Arendal Hospitals in Norway. These hospitals hosted separate colonoscopy screening units for a randomized colonoscopy screening trial (NordICC; Nordic-European Initiative on Colorectal Cancer)Clinicaltrials.gov identifier NCT00883792 [7]. The NordICC trial started in 2011 in Kristiansand and in 2012 in Arendal, and enrolled individuals 55-64 years old until December 2014. The hospitals involved hosted both clinical outpatient colonoscopies as well as screening colonoscopies in NordICC. No other CRC screening activities were present throughout the study period in the hospital's catchment area and CRC screening is not a public health service in Norway. The inclusion period for the present study was 1 January 2013 to 31 December 2014. Eight endoscopists who were performing both screening and clinical colonoscopies during the study period were included in the analyses. Data for each colonoscopy was prospectively recorded by the endoscopist on the standardized forms of the Norwegian quality register Gastronet which includes patients 18 years or older. Gastronet is approved by the National Data Inspectorate and the Directorate of Health. Signed consent from the patients is waived.

The primary outcome of the study was the proportion of colonoscopies with a finding of at least one polyp with a diameter of $5 \mathrm{~mm}$ or more (PDR-5 mm). This was recorded in the Gastronet form as "number of polyps measuring $\geq 5 \mathrm{~mm}$ ". Endoscopists were aware that PDR- $5 \mathrm{~mm}$ as well as a range of other quality indicators were recorded for individual endoscopists as this has been a quality measure reported in the annual reports from Gastronet since its start in 2003. Polyp size was estimated by the endoscopist using a biopsy forceps or polypectomy snare as reference. Photo documentation was not a requirement. Histopathology of the polyps was not retrieved for the study as it is not part of the data collected in Gastronet. Bowel cleansing quality was determined using the Boston Bowel Preparation Scale (BBPS) [8]. BBPS $<6$ was classified as poor and BBPS $\geq 6$ as adequate. Cecal intubation rate was defined as the proportion of colonoscopies with intubation of the cecum divided by the total number of colonoscopies (without adjustments for poor cleansing or strictures).

Colonoscopists in the NordICC study were recruited from the pool of endoscopists employed in routine clinics in the two hospitals. Selection mechanisms for recruitment were not known. To estimate the generalizability of findings when comparing PDR-5 mm in clinics and screening performed by the same endoscopists, PDR-5mm in a purely routine clinical setting were compared for colonoscopies performed by study and non-study endoscopists, respectively.

\section{Statistics}

The Kruskal - Wallis test was used to test the difference in the distribution of age between clinical and screening colonoscopies. The Chi-squared test was used for categorical variables. Univariate and multivariate logistic regression analyses were performed to calculate odds ratio (OR) and $95 \%$ confidence intervals $(95 \% \mathrm{Cl})$ for the detection of polyps $>5 \mathrm{~mm}$ with the following covariates: endoscopy center category (routine or screening clinic), patient's gender, age, cecum intubation, Boston Bowel Preparation Scale (BBPS) score for bowel cleansing, and endoscopist. The covariates were included following this order in a stepwise procedure. For each time a covariate was included in the model, the full model was compared with the previous model using the likelihood ratio test. In the multivariable models, when a variable had missing values, we applied the missing-indicator method, by using a dummy variable to indicate whether the value for that variable was missing. Finally, we performed a sensitivity analysis by randomly selecting a subpopulation with an equal number of colonoscopies performed by each endoscopist in routine and screening clinics ( $\triangleright$ Supplementary Table1). Statistical significance was defined as $P<0.05$ using two-sided tests. The statistical software IBM SPSS 24.0 (IBM Corp, Armonk, New York, USA) and SAS 9.4 (SAS, Cary, NC, USA) were used.

\section{Results}

During the study period, 2939 and 771 colonoscopies were performed in the routine clinics versus screening centers, respectively ( $\triangleright$ Fig. 1). Polyps $\geq 5 \mathrm{~mm}$ were detected in 767 (26\%) of 2939 clinical colonoscopies compared to 240 (31\%) of 771 at the screening centers, OR $1.28(1.08-1.53)(P=0.005)(\triangleright \mathrm{Ta}-$ ble 1, Table 2). There was a slight imbalance between colonoscopies performed in routine clinics and screening units for gender, age, and bowel preparation quality ( $>$ Table $\mathbf{1}$ ).

In the logistic regression models, sex, age, cecal intubation rate, and bowel cleansing were all independent predictors for PDR-5 mm $(P<0.05)$, but the OR for polyp detection in clinics versus screening units did not change meaningfully after the inclusion of those variables ( $\triangleright$ Table 2 ). When the endoscopists were included in the model, there was no longer any difference in PDR-5 mm between screening and clinical colonoscopies, OR $1.04(0.85-1.27)$ (likelihood ratio test for comparison of the models with and without endoscopist as covariate, $P<0.001$ ). 
Colonoscopies (CS) January 2013 - December 2014 serving the population in the Kristiansand and Arendal area. $n=5106$

\begin{tabular}{l|l}
$\begin{array}{l}\text { Gender not stated } \\
\mathrm{n}=3\end{array}$ & $\begin{array}{l}\text { CS performed by } \\
\text { endoscopists } \\
\text { engaged only in } \\
\text { routine clinics } \\
\mathrm{n}=1393\end{array}$ \\
\end{tabular}

CS performed by endoscopists engaged in both routine and screening clinics $\mathrm{N}=3710$

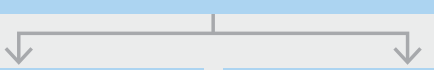

CS in routine clinics (65\% due to symptoms) $\mathrm{n}=2939$

$\downarrow$

Detection of polyps $\geq 5 \mathrm{~mm}$ diameter

- Fig. 1 Flow chart for this study.

This OR approached significance level when restricting the analysis to cases with stated symptoms in the clinical unit and strictly primary screening in the screening unit (OR 1.23 $(0.97-1.55)$ ( $\triangleright$ Table 2$)$. This implies that endoscopist is the key variable explaining different PDR-5mm in screening and clinical colonoscopies and that PDR-5 mm appears similar in clinical and screening colonoscopies for individual endoscopists while this is less consistent for PDR-any-size ( $\bullet$ Table $\mathbf{3}$ ).

Findings in a subpopulation consisting of an equal number of colonoscopies in clinics and screening units per endoscopist verified these results ( $\vee$ Supplementary Table 1 ), showing similar PDR- $5 \mathrm{~mm}$ in routine and screening colonoscopies for both men and women.

In routine clinics, study endoscopists had slightly higher PDR-5 mm (26\%) than non-study endoscopists not engaged in screening $(22 \%)(P=0.003)(\triangleright$ Table 4$)$. A logistic regression analysis adjusting for gender, age, BBPS, cecal intubation status, and indication for colonoscopy, showed an odds ratio for detection of polyps in routine clinics of $1.23(95 \% \mathrm{Cl} 1.05-1.44)(P=$ 0.010 ) for study versus non-study endoscopists.

\section{Discussion}

The well documented inverse relationship between ADR and post-colonoscopy cancer has emphasized the importance of $A D R$ as a quality measure in screening colonoscopy. In routine clinics, however, there are a variety of factors likely to influence both ADR and PDR independent of good or poor colonoscopy performance. Thus, in spite of having adopted screening-based ADRs into routine clinics by consensus [6], we are still in demand of data to support this. The paper by Corley et al. com- prising more than 250000 colonoscopies of which $55 \%$ were diagnostic and $13 \%$ screening, did, however, show a strong correlation between $A D R$ in screening and diagnostic colonoscopy [2].

The present study provides data to suggest that benchmark thresholds for PDR may be set similar for screening and routine clinics, at least for PDR-5 mm. The apparent difference is due to the endoscopists and not to differences in case mix, provided that the screening colonoscopies are genuinely primary screening examinations and not work-up colonoscopies of screen-positives by other screening modalities, e. g. by immunochemical testing for fecal occult blood (iFOBT). This is in line with findings of others concluding that the adenoma-to-polyp detection ratio is endoscopist- and bowel cleansing-related rather than patient-related [9].

Within a group of persons referred for symptoms, patient mix may vary depending on epidemiology, local tradition, and access to colonoscopy. This may cause differences in PDR not related to quality of performance as described by others [10]. In the present study, we have no access to data to differentiate reasons for referral within the category of patients with symptoms. Additionally, if there is a local policy of frequent polyp surveillance, and a high proportion of low risk individuals with irritable bowel syndrome, this may render a low PDR-erroneously suggesting poor quality in performance of colonoscopy. Thus, the validity of both PDR and ADR in routine clinics may be best when used as a tool for assessment of inter-endoscopist variation within the same community, with shared colonoscopy services to secure similar patient access to colonoscopy and possibilities to adjust for referral bias to endoscopists dedicated to any one particular group of patients. In our study, case mix was different among clinical and screening colonoscopies, but differences in age, sex, and bowel cleansing quality did not affect the PDR- $5 \mathrm{~mm}$. The endoscopist was the sole factor explaining the difference in PDR- $5 \mathrm{~mm}$ of $26 \%$ and $31 \%$ in clinical and screening colonoscopies, respectively.

Polypectomy rate has been suggested as a substitute for the more cumbersome ADR [5]. We believe that polypectomy rate may be very similar to the detection rate of polyps measuring $5 \mathrm{~mm}$ or more since these are the ones most likely subjected to polypectomy. For polyps $\geq 5 \mathrm{~mm}$, a PDR at screening of $34 \%$ for men and $28 \%$ for women in the present study is very much in line with polypectomy rates of $40 \%$ (corresponding to ADR $25 \%$ ) and $30 \%$ (15\% ADR) recommended for men and women, respectively [5]. A recent meta-analysis has suggested an overall PDR-ADR conversion factor of 0.69 , but slightly less $(0.61)$ in a screening setting [11]. According to this, the ADR at the screening clinics in our study should be $34 \% \times 0.61=21 \%$ for men and $28 \% \times 0.61=17 \%$ for women, i. e. very much in line with recommendations. When applying the 0.69 conversion factor for routine clinics in our study, the corresponding ADRs should be $30 \% \times 0.69=21 \%$ and $23 \% \times 0.69=16 \%$, respectively, for men and women attending routine clinics.

When setting up a service with dedicated colonoscopists performing screening colonoscopies, there may be organizational and self-selection biases in the recruitment of endoscopists. In this study, we have shown that study endoscopists 
- Table 1 Characteristics of colonoscopies performed for clinical indications versus colorectal cancer screening.

\begin{tabular}{|c|c|c|c|}
\hline & $\begin{array}{l}\text { Routine clinics } \\
(n=2939)\end{array}$ & $\begin{array}{l}\text { Screening unit } \\
(\mathrm{n}=771)\end{array}$ & $P$ value $^{1}$ \\
\hline \multicolumn{3}{|l|}{ Sex } & \multirow[t]{3}{*}{0.043} \\
\hline - Men & $1370(47)$ & $391(51)$ & \\
\hline - Women & $1569(53)$ & $380(49)$ & \\
\hline Age, median, IQR & $63(52-71)$ & $61(58-63)$ & $<0.001^{2}$ \\
\hline \multicolumn{3}{|l|}{ Indication for colonoscopy } & \multirow[t]{8}{*}{$<0.001$} \\
\hline - Symptoms ${ }^{3}$ & $1908(65)$ & $6(0.8)$ & \\
\hline - Polyp control & $476(16)$ & $7(0.9)$ & \\
\hline - Screening & $15(0.5)$ & $746(97)$ & \\
\hline - CRC control & $91(3.1)$ & $1(0.1)$ & \\
\hline - CRC in family & $185(6.3)$ & $8(1.0)$ & \\
\hline - IBD control & $140(4.8)$ & 0 & \\
\hline - Other indications & $81(2.8)$ & 0 & \\
\hline - Indication not stated & $43(1.5)$ & $3(0.4)$ & \\
\hline \multicolumn{3}{|l|}{ BBPS score } & \multirow[t]{4}{*}{$<0.001$} \\
\hline - $<6$ points & $276(9)$ & $32(4)$ & \\
\hline - $\geq 6$ points & $2319(79)$ & $716(93)$ & \\
\hline - Missing & $344(12)$ & $23(3)$ & \\
\hline \multicolumn{4}{|l|}{ Cecum intubation status } \\
\hline - Cecum reached & $2723(93)$ & $726(94)$ & \multirow[t]{3}{*}{0.082} \\
\hline - Cecum not reached & $122(4)$ & $32(4)$ & \\
\hline - Intubation status not stated & $94(3)$ & $13(2)$ & \\
\hline \multicolumn{4}{|l|}{ Endoscopist } \\
\hline . 1 & $467(16)$ & $76(10)$ & \multirow[t]{8}{*}{$<0.001$} \\
\hline$\cdot 2$ & $437(15)$ & $33(4)$ & \\
\hline .3 & $436(15)$ & $2(0.3)$ & \\
\hline - 4 & $291(10)$ & $106(14)$ & \\
\hline - 5 & $114(4)$ & $189(25)$ & \\
\hline . 6 & $380(13)$ & $206(27)$ & \\
\hline .7 & $107(4)$ & $104(14)$ & \\
\hline - 8 & 707 (24) & $55(7)$ & \\
\hline \multicolumn{4}{|l|}{ Polyp $(\mathrm{s}) \geq 5 \mathrm{~mm}$} \\
\hline - Men & $408(30)$ & $134(34)$ & 0.089 \\
\hline - Women & $358(23)$ & $106(28)$ & 0.037 \\
\hline - Total & $766(26)$ & $240(31)$ & 0.005 \\
\hline \multicolumn{4}{|c|}{$\begin{array}{l}\text { CS, colonoscopy; CRC, colorectal cancer; IBD, inflammatory bowel disease; BBPS, Boston Bowel Preparation Scale; IQR, interquartile range. } \\
{ }^{1} \text { Chi-squared test, apart from Kruskal-Wallis test. } \\
2 \text { Kruskal-Wallis test. } \\
{ }^{3} \text { In the screening unit, participants may appear with rather than because of symptoms. Participants for screening were drawn from the population registry without } \\
\text { knowledge of symptoms. }\end{array}$} \\
\hline
\end{tabular}


- Table 2 Odds ratios for the detection of polyps $>5 \mathrm{~mm}$ diameter at colonoscopy in screening center versus routine clinics - total (A) and restricted to those attending with explicit "screening" as indication at the screening centers and explicit "symptoms" as indication in the routine clinics (B).

\begin{tabular}{|l|l|l|}
\hline \begin{tabular}{l} 
Covariates in the model \\
\hline Clinical CS
\end{tabular} & $\begin{array}{l}\text { A: Screening center vs routine clinics, } \\
\text { OR } \mathbf{( 9 5 \% C I )}\end{array}$ & $\begin{array}{l}\text { B: Indication screening (at screening center) vs } \\
\text { symptoms (in routine clinics), OR (95\%Cl) }\end{array}$ \\
\hline Clinical CS, sex & $1.28(1.08-1.53)$ & $1.55(1.28-1.87)$ \\
\hline Clinical CS, sex, age & $1.27(1.06-1.51)$ & $1.50(1,24-1.82)$ \\
\hline Clinical CS, sex, age, CIS & $1.32(1.11-1.58)$ & $1.60(1.32-1.94)$ \\
\hline Clinical CS, sex, age, CIS, BBPS & $1.34(1.12-1.60)$ & $1.60(1.32-1.94)$ \\
\hline Clinical CS, sex, age, CIS, BBPS, endoscopist & $1.04(0.85-1.27)$ & $1.57(1.29-1.91)$ \\
\hline OR, odds ratio; CS, colonoscopy; CI, confidence interval; CIS, cecum intubation status; BBPS, Boston Bowel Preparation Scale.
\end{tabular}

- Table 3 Polyp detection rates (\%) for individual endoscopists engaged in both clinical and screening colonoscopies.

\begin{tabular}{|c|c|c|c|c|c|c|}
\hline \multirow{2}{*}{$\begin{array}{l}\text { Endos- } \\
\text { copist no. }\end{array}$} & \multicolumn{3}{|l|}{ PDR-5 mm } & \multicolumn{3}{|l|}{ PDR-any-size } \\
\hline & Clinical CS & Screening CS & $P$ value $^{1}$ & Clinical CS & Screening CS & $P$ value $^{1}$ \\
\hline 1 & 79/467 (17) & $18 / 76(24)$ & 0.153 & $136 / 467$ (29) & 29/76 (38) & 0.112 \\
\hline 2 & $73 / 437(17)$ & $4 / 33(12)$ & 0.493 & $85 / 437(20)$ & $6 / 33(18)$ & 0.859 \\
\hline 3 & $108 / 436(25)$ & $1 / 2(50)$ & 0.410 & $122 / 436(28)$ & $1 / 2(50)$ & 0.489 \\
\hline 4 & $114 / 291$ (39) & 41/106 (39) & 0.929 & $119 / 291(41)$ & $43 / 106(41)$ & 0.953 \\
\hline 5 & $55 / 114(48)$ & 73/189 (39) & 0.100 & $77 / 114(68)$ & $111 / 189$ (59) & 0.126 \\
\hline 6 & $87 / 380(23)$ & $51 / 206(25)$ & 0.612 & $99 / 380(26)$ & $75 / 206(36)$ & 0.009 \\
\hline 7 & $32 / 107(31)$ & $37 / 104(36)$ & 0.380 & $38 / 107(36)$ & $45 / 104(43)$ & 0.249 \\
\hline 8 & $218 / 707$ (31) & $15 / 55(27)$ & 0.581 & $235 / 707$ (33) & $16 / 55$ (29) & 0.528 \\
\hline Total & $766 / 2939(26)$ & $240 / 771(31)$ & 0.005 & $911 / 2939(31)$ & $326 / 771(42)$ & $<0.001$ \\
\hline
\end{tabular}

CS, colonoscopy; PDR- $5 \mathrm{~mm}$, polyp detection rate for polyps $5 \mathrm{~mm}$ or larger in diameter; PDR-any-size, polyp detection rate for polyps of any size.

${ }^{1}$ Chi-squared test.

performing both routine and screening colonoscopies had higher PDR-5 mm (26\%) in their routine clinics than non-study endoscopists (PDR 22\%) performing only routine clinical colonoscopies. This may be caused by selection bias in the recruitment of endoscopists or their screening engagement may have raised their awareness of polyps also in routine clinical work. The latter is more likely since these endoscopists collectively had a PDR- $5 \mathrm{~mm}$ of $19 \%$ during the last year before the NordICC screening trial started (unpublished data from Gastronet). Thus, patients for some reason attending routine clinics for a colonoscopy, may profit additionally in terms of reduced future CRC risk if subjected to a colonoscopist also engaged in screening colonoscopy with a dedicated focus on colorectal polyp detection.

In publications investigating PDR, the definition of polyps that are included varies. In two papers from the same research group using polypectomy rate (PR) as a proxy for $A D R$, one included polyps subjected to "biopsy or snare removal" [5]. The other paper informed additionally that most endoscopists adhered to "removal of all polyps with the exception of small, hy- perplastic-appearing distal polyps, of which the endoscopist should obtain biopsy samples" and any registered biopsy counted as polypectomy, including biopsied small lesions [4]. Thus, there may be uncertainties about which polyps are included in the PR concept. For practical purposes, polyps $<5 \mathrm{~mm}$ are most likely ignored or biopsied (and up to $80 \%$ of them may not be adenomas [12]) while polyps $\geq 5 \mathrm{~mm}$ are usually suited for true polypectomy by snare and most of these are adenomas. Therefore, if choosing to use PDR- $5 \mathrm{~mm}$ as a quality indicator until ADR can be made more easily accessible, PR or PDR restricted to polyps $\geq 5 \mathrm{~mm}$ may be more valid as a proxy for ADR than a global PDR including diminutive polyps with dominantly non-adenomatous histology.

There are several strengths to this study. First of all, screening and routine clinical colonoscopies were performed by the same endoscopists after run-in periods for participation in quality assurance and screening engagement. We have hypothesized that the technical scrutiny of a screenee colon and a patient colon would be the same when performed by the same endoscopist within the same hospital with similar framework, 
- Table 4 Characteristics of colonoscopies in routine clinics only, performed by endoscopists working in clinics only compared to study endoscopists engaged both in the local routine and screening clinics.

\begin{tabular}{|c|c|c|c|}
\hline & $\begin{array}{l}\text { Clinical CS by endoscopist engaged in } \\
\text { routine clinics only }(n=1391)\end{array}$ & $\begin{array}{l}\text { Clinical CS by endoscopist engaged in } \\
\text { routine and screening clinics }(n=2939)\end{array}$ & $P$ value \\
\hline \multicolumn{3}{|l|}{ Sex } & \multirow[t]{3}{*}{0.023} \\
\hline - Men & $597(43)$ & $1370(47)$ & \\
\hline - Women & $794(57)$ & $1569(53)$ & \\
\hline Age, median, IQR & $66(54-75)$ & $63(52-71)$ & $<0.001$ \\
\hline \multicolumn{4}{|l|}{ Indication } \\
\hline - Symptoms & $908(65)$ & $1908(65)$ & \multirow[t]{3}{*}{$<0.001$} \\
\hline - Polyp control & $136(9.8)$ & $476(16)$ & \\
\hline - Other or missing & $347(25)$ & $555(19)$ & \\
\hline \multicolumn{3}{|l|}{ BBPS score } & \multirow[t]{4}{*}{0.018} \\
\hline - <6 points & $155(11)$ & $276(9)$ & \\
\hline - $\geq 6$ points & $1044(75)$ & $2319(79)$ & \\
\hline - Missing & $192(14)$ & $344(12)$ & \\
\hline \multicolumn{4}{|l|}{ Cecum intubation } \\
\hline - Cecum reached & $1277(92)$ & $2723(93)$ & \multirow[t]{3}{*}{0.304} \\
\hline - Cecum not reached & $72(5.2)$ & $122(4.1)$ & \\
\hline - Intubation status not stated & $42(3.0)$ & $94(3.2)$ & \\
\hline \multicolumn{4}{|l|}{ Polyp $\geq 5$ mm } \\
\hline - Men & $151(25)$ & $408(30)$ & 0.042 \\
\hline - Women & $155(20)$ & $358(23)$ & 0.066 \\
\hline - Total & $306(22)$ & $766(26)$ & 0.004 \\
\hline
\end{tabular}

staff, and timeslots per colonoscopy. This was supported by the present data. Second, once a polyp has been detected, it is not very likely that the same endoscopist would use a different polyp size estimate in screening and routine colonoscopy. With this design, over- and underestimations of size may be assumed to have a similar distribution in a screening and a routine clinical setting, i.e. any potential gaming would be expected to be similarly distributed in screening and routine non-screening clinics. We have provided data on PDR-any-size in $>$ Table 3 to show inter-endoscopist variations in relation to PDR-5 mm. Since endoscopists may have different practice in reporting minute polyps in the rectum, a ratio between PDR- $5 \mathrm{~mm}$ and PDR-any-size may not be a good estimate for variation in size estimates and gaming. Variations in reporting on minute rectal polyps may be a reason for poor correlation between ADR and PDR in the rectum and left colon in contrast to more proximal segments $[13,14]$. Third, this is a study from two non-university public hospitals serving an average risk population in Norway. Finally, both screenees and patients are recruited from the same background population.

An inherent weakness of this study is the use of PDR with subjective estimates of polyp size instead of ADR which is more objective. Also, underreporting of polyps may have occurred. These weaknesses were, however, aimed to be compensated by recruiting the same endoscopists to do both the routine and screening colonoscopies as we expected frequency of reporting and subjective size estimates by the same endoscopist to be similar in either setting - as stated above. Also, it would have been helpful if we had detailed descriptions of indications for colonoscopies within the symptomatic group of patients.

In conclusion, this observational study on a well established colonoscopy screening unit and routine clinical colonoscopies performed by the same endoscopists, suggests that benchmarks for PDR-5 mm may be set similar for primary screening and routine clinical colonoscopies. The validity of PDR-5 mm (and probably ADR) in routine clinics may, however, easily be disturbed by changes in disease epidemiology, differences in access, and local tradition for primary referral to colonoscopy and surveillance. Therefore, PDR-5 mm in routine clinics is best suited for quality assurance within a community with similar access to colonoscopy resources and referral traditions. 


\section{Competing interests}

Yes. Geir Hoff received payment from Amgen Norway in 2017 for giving a lecture at a medical conference.

\section{References}

[1] Kaminski MF, Regula J, Kraszewska E et al. Quality indicators for colonoscopy and the risk of interval cancer. NEJM 2010; 362: 1795-1803

[2] Corley DA, Jensen CD, Marks AR et al. Adenoma detection rate and risk of colorectal cancer and death. NEJM 2014; 370: 1298-1306

[3] Rex DK, Schoenfeld PS, Cohen J et al. Quality indicators for colonoscopy. Gastrointest Endosc 2015; 81: $31-53$

[4] Williams JE, Le TD, Faigel DO. Polypectomy rate as a quality measure for colonoscopy. Gastrointest Endosc 2011; 73: 498 - 506

[5] Williams JE, Holub JL, Faigel DO. Polypectomy rate is a valid quality measure for colonoscopy: results from a national endoscopy database. Gastrointest Endosc 2012; 75: 576 - 582

[6] Kaminski MF, Thomas-Gibson S, Bugajski M et al. Performance measures for lower gastrointestinal endoscopy: a European Society of Gastrointestinal Endoscopy (ESGE) Quality Improvement Initiative. Endoscopy 2017; 49: $378-397$
[7] Bretthauer M, Kaminski MF, Loberg M et al. Population-based colonoscopy screening for colorectal cancer: a randomized clinical trial. JAMA Int Med 2016; 176: 894 - 902

[8] Lai EJ, Calderwood AH, Doros G et al. The Boston bowel preparation scale: a valid and reliable instrument for colonoscopy-oriented research. Gastrointest Endosc 2009; 69: 620-625

[9] Francis DL, Rodriguez-Correa DT, Buchner A et al. Application of a conversion factor to estimate the adenoma detection rate from the polyp detection rate. Gastrointest Endosc 2011; 73: 493 - 497

[10] Boroff ES, Disbrow M, Crowell MD et al. Adenoma and polyp detection rates in colonoscopy according to indication. Gastroenterol Res Pract 2017; 2017: 7207595

[11] Niv Y. Polyp detection rate may predict adenoma detection rate: a meta-analysis. Eur J Gastroenterol Hepatol 2018; 30: 247 - 251

[12] Klein JL, Okcu M, Preisegger KH et al. Distribution, size and shape of colorectal adenomas as determined by a colonoscopist with a high lesion detection rate: Influence of age, sex and colonoscopy indication. United Eur Gastroenterol ] 2016; 4: 438-448

[13] Boroff ES, Gurudu SR, Hentz JG et al. Polyp and adenoma detection rates in the proximal and distal colon. Am J Gastroenterol 2013; 108: $993-999$

[14] Gohel TD, Burke CA, Lankaala P et al. Polypectomy rate: a surrogate for adenoma detection rate varies by colon segment, gender, and endoscopist. Clin Gastroenterol Hepatol 2014; 12: 1137 - 1142 
- Supplementary Table 1 Supplementary Characteristics of colonoscopies performed in routine and screening clinics. Subpopulation with equal number of colonoscopies performed by each endoscopist in routine and screening clinics. If, for example, an endoscopist performed $m$ colonoscopies in the routine clinics and $n$ in the screening clinics, with $m>n$, then we randomly selected only $n$ colonoscopies performed in the routine clinics.

\begin{tabular}{|c|c|c|c|}
\hline & $\begin{array}{l}\text { Routine } \\
(n=696)\end{array}$ & $\begin{array}{l}\text { Screening } \\
(n=696)\end{array}$ & $P$ value $^{1}$ \\
\hline \multicolumn{4}{|l|}{ Sex } \\
\hline - Men & $330(47)$ & $354(51)$ & \multirow[t]{2}{*}{0.198} \\
\hline - Women & $366(53)$ & $342(49)$ & \\
\hline Age, median, IQR & $63(54-72)$ & $61(58-63)$ & $<0.001^{2}$ \\
\hline \multicolumn{4}{|l|}{ Indication for colonoscopy } \\
\hline - Symptoms & $420(60)$ & 0 & \multirow[t]{4}{*}{$<0.001$} \\
\hline - Polyp control & $148(21)$ & 0 & \\
\hline - Screening & $0(0)$ & $673(97)$ & \\
\hline - Other or missing & $128(18)$ & $23(3)$ & \\
\hline \multicolumn{3}{|l|}{ BBPS score (mean, $95 \% \mathrm{Cl}$ ) } & \multirow[t]{4}{*}{$<0.001$} \\
\hline - $<6$ points & $49(7)$ & $27(4)$ & \\
\hline - $\geq 6$ points & $580(83)$ & $649(93)$ & \\
\hline - Missing & $67(10)$ & $20(3)$ & \\
\hline \multicolumn{4}{|l|}{ Cecum intubation status } \\
\hline - Cecum reached & $638(92)$ & $657(94)$ & \multirow[t]{3}{*}{0.130} \\
\hline - Cecum not reached & $37(5)$ & $26(4)$ & \\
\hline - Intubation status not stated & $21(3)$ & $13(2)$ & \\
\hline \multicolumn{4}{|l|}{ Endoscopist no. } \\
\hline - 1 & $76(11)$ & $76(11)$ & \multirow[t]{8}{*}{-} \\
\hline - 2 & $33(5)$ & $33(5)$ & \\
\hline - 3 & $2(0.3)$ & $2(0.3)$ & \\
\hline .4 & $106(15)$ & $106(15)$ & \\
\hline - 5 & $114(16)$ & $114(16)$ & \\
\hline .6 & $206(30)$ & $206(30)$ & \\
\hline .7 & $104(15)$ & $104(15)$ & \\
\hline .8 & $55(8)$ & $55(8)$ & \\
\hline \multicolumn{4}{|l|}{ Polyp $(\mathrm{s}) \geq 5 \mathrm{~mm}$} \\
\hline - Men & $112(34)$ & $119(34)$ & 0.929 \\
\hline - Women & $92(25)$ & $91(27)$ & 0.655 \\
\hline - Total & 204 (29) & $210(30)$ & 0.725 \\
\hline $\begin{array}{l}\text { BBPS, Boston Bowel Preparation Sc } \\
{ }^{1} \text { Chi-squared test, apart from Krus } \\
{ }^{2} \text { Kruskal-Wallis test. }\end{array}$ & & & \\
\hline
\end{tabular}

